\title{
The Air Spora of a Cowshed
}

\author{
BY H. K. BARUAH \\ University of Gauhati, Assam, India
}

(Received 17 February 1961

\begin{abstract}
SUMMARY
Study of the air spora of a cowshed by means of a Hirst Automatic Volumetric Spore Trap showed an atmospheric concentration of fungal spores ranging from 95,000 to $16,000,000$ spores $/ \mathrm{m}^{3}$. There was a direct relationship between the hours during which hay was being fed and the highest concentrations of spores. Aspergillus-Penicillium and Mucor types of spore were predominant, and hyphal fragments including conidiophores were the third most numerous component. The findings are discussed with reference to human and animal fungal disease.
\end{abstract}

\section{INTRODUCTION}

Although progress has been made in the study of the outdoor air spora there is little information on the air spora within buildings (see Maunsell, 1954; Gregory, Hirst \& Last, 1953; Richards, 1954). Ainsworth (see Fuller, 1953) in a short series of Petri dish exposures found the fungus spore concentration in cowsheds to be 10-100 times that of the farmyard air. Rolle \& Kolb (1954) using a similar method obtained Absidia ramosa, Mucor pusillus, Aspergillus fumigatus, A. flavus, A. niger, $A$. glaucus (series), and Scopulariopsis brevicaulis in abundance in farm buildings. They also isolated most of these species from adjacent samples of hay and from the saliva of the housed cattle. Ainsworth \& Austwick $(1955 a, b)$ confirmed that these species (and especially Absidia ramosa and Aspergillus fumigatus) were constantly associated with farm animals and could be isolated from almost every bovine and equine skin scraping received for examination as suspected ringworm. These few records of fungi from the environment of farm animals clearly show that the species present are just those responsible for the commoner systemic mycoses of man and animals in Britain. Aspergillosis in birds and mammals, mucormycosis in cattle, pigs and man, and bovine mycotic abortion are all associated with these fungi in their pathogenic state, yet the spores of these potential pathogens are normally present in the atmosphere of farm buildings. A key to the sporadic occurrence of these mycoses may be found in the quantitative and qualitative comparison of the air spora of cowsheds where animals are housed under normal conditions with those premises in which mycoses such as mycotic abortion have occurred. The preliminary study of the air spora of a cowshed reported here was carried out at the Ministry of Agriculture, Fisheries and Food, Central Veterinary Laboratory, Weybridge, Surrey, England, during November and December 1956. 


\section{METHODS}

Building. The cowshed was a modern brick and concrete building with a concrete floor, $98.0 \mathrm{~m}$. long, $11.4 \mathrm{~m}$. wide, $5.0 \mathrm{~m}$. to the top of the sloping roof and $2.0 \mathrm{~m}$. to the top of the side walls. The cubic capacity was thus about $750 \mathrm{~m}^{3}$ (Fig. 1). The number of milking cows housed was 24 . The hay in use for feeding during the period of the experiment was of fair quality.

Sampling. A Hirst Automatic Volumetric Spore Trap (AVST) mounted on a tripod, bringing the aperture $0.5 \mathrm{~m}$. from the floor, was used for sampling. It was sited approximately in the centre of the north access passage of the outside of the stalls. The aperture was facing and $0.5 \mathrm{~m}$. away from the manger which was of concrete construction and had an outside wall $1 \mathrm{~m}$. high (see Fig. 1). In this way the trap was within $2 \mathrm{~m}$. of the head of the nearest animal. The pump was operated from a mains electricity supply.

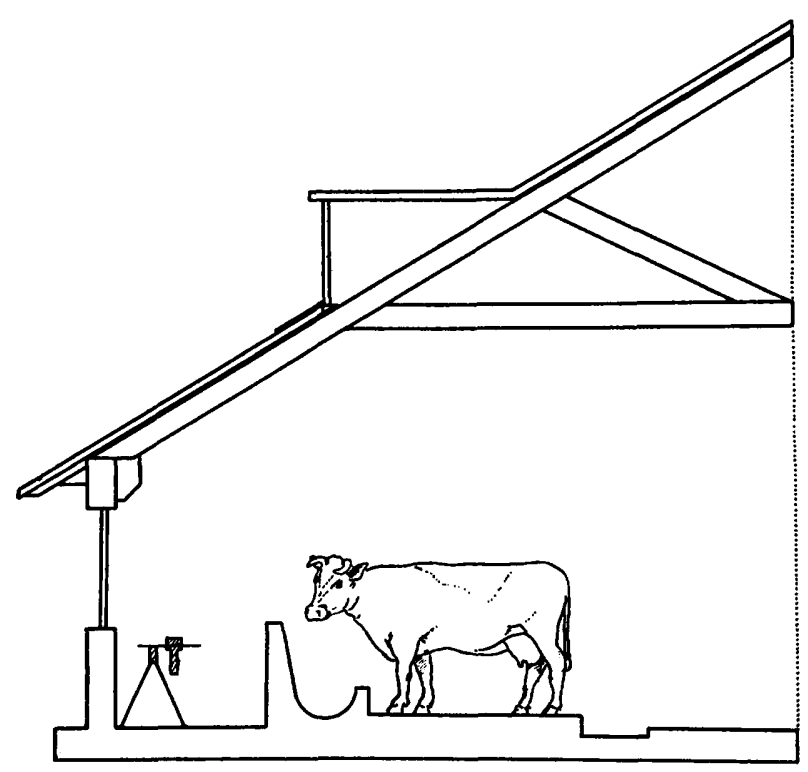

Fig. 1. Diagram of position of spore trap in cowshed.

The rate of flow was adjusted to approximately 10.0 1./min. and keyed 'Vaseline'coated slides were used for the trace (Hirst, 1953). The slide moved at $2 \mathrm{~mm}$. $/ \mathrm{hr}$. and the $24 \mathrm{hr}$. trace was thus $48 \mathrm{~mm}$. long. Slides were changed at $17.00 \mathrm{hr}$. daily and the trap was operated continuously for periods of 4 days at a time. The two periods selected for analysis were 12-16 and 19-23 November 1956 inclusive. The weather during the first period was damp and mild with dense fog on the night of 13 November; during the second period it was fine and cold with a severe frost on the night of 22 November.

Scanning. After mounting in 'Solvar'-lactophenol scanning was carried out by means of short or cross traverses (Hirst, 1953). At certain periods of the day so many spores were being caught that the deposit was too thick for scanning, and these periods were therefore sampled separately on 18 December by using 
0.5-2.5 min. exposures from which the spore content at these times could be effectively calculated.

Classification of spores. The spores were classified into seven easily recognizable groups with a group for hyphal fragments, chiefly conidiophores.

Methods for the calculation of spore content. From the rate of movement of the slide in the trap, the volume of air drawn into the trap and the area of trace scanned in counting, the number of spores $/ \mathrm{m}^{3}$ air at different times of the day could be estimated.

Operations in the cowshed. Operations carried out in the cowshed appeared to be largely responsible for the changes in the concentration of spores in the air; a summary of the routine procedures is given in Table 1. The time of each operation varied slightly but the amount was not more than $\pm 0.5 \mathrm{hr}$.

Table 1. Daily operations in coroshed

$\begin{array}{ll}07.00 & \text { Bedding straw and dung cleared out. Cows washed down } \\ 08.00 & \text { Cake fed and cows milked } \\ 09.15 & \text { Kale and hay fed } \\ 10.15 & \text { Cows groomed and turned out to pasture } \\ 10.30 & \text { Dung cleared out and mangers cleaned, forestall swept and } \\ \text { cowshed hosed out } \\ 13.30 & \begin{array}{c}\text { Kale and hay (in bales) brought in to access passages and } \\ \text { bedding straw put down }\end{array} \\ 14.45 & \text { Cows brought in from pasture and washed down } \\ 15.15 & \text { Cake fed and cows milked } \\ 15.30 & \text { Hay and kale fed, cows bedded up and floor washed down } \\ 16.00 & \text { Cowshed closed }\end{array}$

Supplementary methods of sampling. In addition to the visual sampling with the automatic volumetric suction trap two cultural methods were also used. In one suggested by Professor A. J. P. Oort (University of Wageningen) and used in conjunction with the suction trap, the slides were tightly covered with a $2.5 \mathrm{~cm}$. wide strip of washed semi-transparent plastic film ('Polythene') which was then smeared lightly with a commercial pectic jelly prepared from apple ('appelstroop'). Slides so prepared were then exposed in the suction trap and after exposure the plastic was carefully removed and cut up transversely into four strips $12 \mathrm{~mm}$. wide. These were placed in $50 \mathrm{ml}$. sterile distilled water, shaken to produce an even suspension, and then dilutions were mixed with molten $2 \%$ malt agar in Petri dishes. The second supplementary method of sampling was by the exposure of $10 \mathrm{~cm}$. Petri dishes containing $2 \%$ malt agar to gravity sampling for periods varying from 15 sec. to 5 min. on a table $1 \mathrm{~m}$. above the floor of the cowshed.

\section{RESULTS}

\section{Visual results with the $A$ VST}

The first 4-day period of operation revealed that even with fair quality hay the cowshed air spora was very much heavier than had been imagined, and that the peak periods of spore deposition corresponded to the times at which the hay was handled. These periods occurred just after milking in the morning, in the early afternoon, and again after milking in mid-afternoon. Because the traces at these times were 
too thick for scanning and separate sampling had been undertaken for the peak periods, it has been necessary to divide the observations into peak and off-peak periods, the latter alone being based on continuous sampling. The daily off-peak means are thus calculated over nine 2-hourly observations on 8 days and the peak period means are based on two traces obtained within 5 min. of each other at 16.45 hr. on 18 December. The data on the atmospheric spore content of the cowshed are summarized in Table 2.

Table 2. Concentrations of spores in corvshed air

Figures are for 8-day readings.

\begin{tabular}{|c|c|c|c|c|c|c|}
\hline \multirow[b]{4}{*}{ Spore type } & \multicolumn{6}{|c|}{ Spore content thousands $/ \mathrm{m}^{3}$} \\
\hline & \multicolumn{3}{|c|}{ Off-peak } & \multirow[b]{3}{*}{$\begin{array}{c}\text { Peak } \\
\text { average }\end{array}$} & & \\
\hline & \multirow[b]{2}{*}{$\begin{array}{c}\text { Daily } \\
\text { average }\end{array}$} & \multicolumn{2}{|c|}{ Hourly } & & \multicolumn{2}{|c|}{ Total percentage } \\
\hline & & Highest & Lowest & & Off-peak & Peak \\
\hline Aspergillus* & $\mathbf{3 2 \cdot 6}$ & $500 \cdot 0$ & $1 \cdot 3$ & 12,390 & $34 \cdot 2$ & $75 \cdot 1$ \\
\hline Mucor type & $\mathbf{3 3} \cdot \mathbf{0}$ & $144 \cdot 0$ & $1 \cdot 0$ & 1,217 & $34 \cdot 6$ & $7 \cdot 4$ \\
\hline Cladosporium & 6.9 & $\mathbf{8 6} \cdot 0$ & 0.7 & $\mathbf{1 , 5 7 0}$ & $7 \cdot 2$ & $\mathbf{9 \cdot 5}$ \\
\hline Ustilago & $\mathbf{0 . 3}$ & $\mathbf{2 \cdot 2}$ & 0.0 & 168 & 0.8 & $1 \cdot 0$ \\
\hline Monotospora & $1 \cdot 0$ & $12 \cdot 0$ & 0.0 & 69 & $\mathbf{1 \cdot 0}$ & $0 \cdot 4$ \\
\hline Hyphae & $16 \cdot 9$ & $60 \cdot 2$ & 0.0 & 851 & $17 \cdot 7$ & $\mathbf{5} \cdot \mathbf{1}$ \\
\hline Streptomyces & . & $5 \cdot 0$ & 0.0 & . & . & - \\
\hline Non-classified & 4.5 & - & • & 232 & $4 \cdot 7$ & $\mathbf{1 \cdot 4}$ \\
\hline Totals: & $95 \cdot 2$ & - & - & 16,497 & $100 \cdot 0$ & $100 \cdot 0$ \\
\hline
\end{tabular}

Total spore concentrations. From the colour and thickness of the spore deposit on the exposed slides (Fig. 2), it was not surprising that the total of spores caught was in excess of any figure previously reported from the AVST. Gregory et al. (1953) recorded the highest concentration of spores with $360,000 / \mathrm{m}^{3}$ in the cellar of an

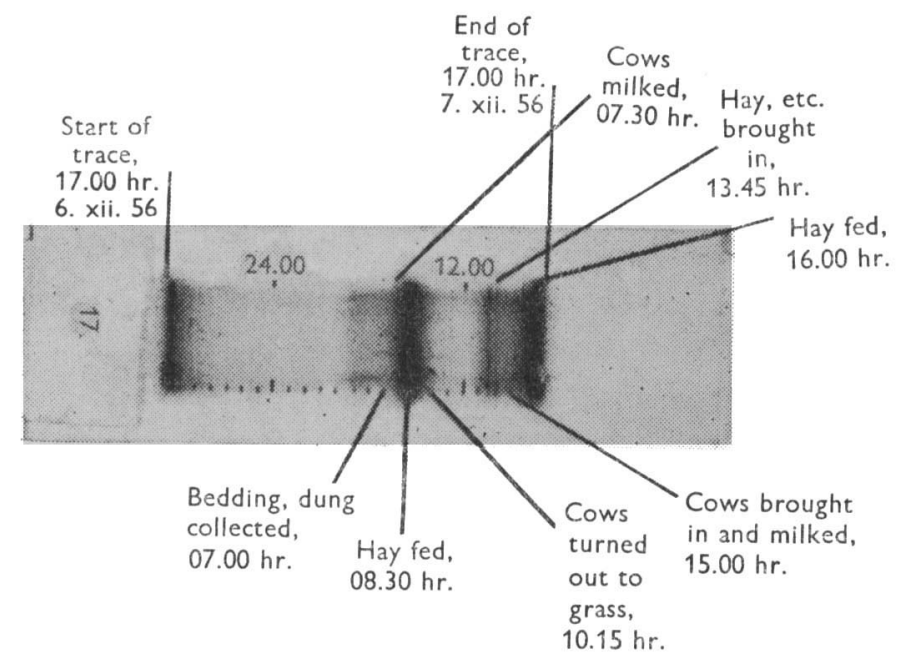

Fig. 2. Slide exposed from $17.00 \mathrm{hr}$. from 6 December to $17.00 \mathrm{hr}$. 7 December 1956. 
old country mansion with large fruiting bodies on Merulius lacrymans a short distance from the trap. The normal level of spores in the outdoor air at $2 \mathrm{~m}$. above the ground level rarely rises above $100,000 \mathrm{spores} / \mathrm{m}^{3}$ (Hirst, 1953), although Sreeramulu (1958) reported over a million spores $/ \mathrm{m}^{3}$. The daily off-peak average spore content recorded in our observations was $95,000 / \mathrm{m}^{3}$; and very large day-today fluctuations were found amongst the individual spore types. On some days over 400 times as many spores of one type were present as on other days. In the peak periods the total spore concentrations reached $16,500,000 / \mathrm{m}^{3}$.

Diurnal periodicity. Unfortunately not enough reliable data were available for analysis of the diurnal periodicity of the spore types and the only comparisons to be drawn are those between peak and off-peak periods. Day-to-day variation of the spore content was very great. In Table 3 the total concentrations at $01.00 \mathrm{hr}$. are given for 4 consecutive days (20-23 November). These show that the numbers of mucoraceous spores at times exceeded the combined total of the other types and that in off-peak periods the spore content of the air varied considerably at the same time each day.

Table 3. Spore content at $01.00 \mathrm{hr}$. on 4 consecutive days

\begin{tabular}{|c|c|c|c|c|}
\hline \multirow[b]{3}{*}{ Spore type } & \multicolumn{4}{|c|}{$\begin{array}{l}\text { Spore content thousands } / \mathrm{m.}^{3} \text { at } 01.00 \mathrm{hr} \text {. } \\
\text { on } 4 \text { consecutive days }\end{array}$} \\
\hline & \multicolumn{4}{|c|}{ Date during November 1956} \\
\hline & 20 & 21 & 22 & 23 \\
\hline Aspergillus & $6 \cdot 6$ & $13 \cdot 1$ & $\mathbf{5 2 \cdot 1}$ & $12 \cdot 7$ \\
\hline Mucor type & $46 \cdot 9$ & $142 \cdot 6$ & $31 \cdot 8$ & $10 \cdot 2$ \\
\hline Cladosporium & $5 \cdot 3$ & $\mathbf{3 . 9}$ & $7 \cdot 1$ & $\mathbf{3 \cdot 0}$ \\
\hline Ustilago & $0 \cdot 6$ & $0 \cdot 0$ & 0.0 & 0.0 \\
\hline Monotospora & $1 \cdot 2$ & 0.0 & $0 \cdot 0$ & $\mathbf{0} \cdot \mathbf{0}$ \\
\hline Hyphae & $9 \cdot 8$ & $12 \cdot 5$ & $17 \cdot 1$ & $15 \cdot 5$ \\
\hline Streptomyces & $0 \cdot 7$ & $\mathbf{2 \cdot 3}$ & 0.0 & $\mathbf{0} \cdot \mathbf{0}$ \\
\hline Non-classified & $6 \cdot 0$ & $\mathbf{2 \cdot 2}$ & $1 \cdot 3$ & $\mathbf{0 . 3}$ \\
\hline Totals & $77 \cdot 1$ & $181 \cdot 6$ & $109 \cdot 4$ & 42.7 \\
\hline
\end{tabular}

\section{Spore types}

The spore types found in the trace did not appear to differ greatly from those found in the outdoor air; only two components, the hyphal fragments and the Monotospora-type spore, were new records. The main interest, however, is that the proportions of the different classes were almost reversed, with Mucor and Aspergillustype spores becoming the predominant forms (combining to give $70 \%$ off-peak and $85 \%$ during peak) and Cladosporium falling to third or fourth place (7 and $9 \%$, respectively).

Mucor type. The characteristic sporangiospores of Mucor and Absidia spp. were noticeably unevenly distributed on the traces, apparently due to the fact that a great many had passed through the aperture of the trap within their sporangia and these bodies had burst on striking the surface of the slide. Many such apparently burst sporangia with the characteristic pear-shaped columellae of Absidia were seen.

Aspergillus type. Although this type of phialospore covers both Aspergillus and 
Penicillium it is believed that the latter is rarer in hay samples and that aspergilli predominate.

Cladosporium type. No great diurnal variation in the numbers of Cladosporium spores which might have corresponded to that seen during the late summer in outdoor air was noted. The highest concentration was above the values previously recorded and it seems that the spores were not derived from the outdoor air. Comparison with the figures of Hirst (1953) shows that Cladosporium spores are only likely to be found in low numbers by the end of October.

Monotospora. M. lanuginosa is one of the commonest fungi found in hay especially when it has been heated during maturation, for it has an optimum growth temperature of $45-50^{\circ}$ (Rehe, 1927). The spores are globose, about $10 \mu$. diam., with thick dark-brown warted walls. This type does not seem to have been reported before as a component of the air spora, but it may have been overlooked because of its close resemblance to a small Epicoccum spore.

Ustilago. Smut spores varied considerably in numbers but were never very abundant with a maximum 2-hourly concentration of $2000 / \mathrm{m} .{ }^{3}$ in an off-peak time. On the last day of sampling, corresponding to an outside heavy air frost, no smut spores were seen.

Streptomyces. Only incomplete figures for the aerial spores of these actinomycetes were obtained, but they are sufficient to indicate that streptomycete spores were a characteristic and probably important part of the cowshed air spora.

Hyphae. Vegetative hyphal fragments and conidiophores are rarely classified as a component of the outdoor air spora, but the figures available from our observations show them to be third in numerical order in off-peak periods and fourth in the peaks. They were very variable and could not always be attributed to a particular fungus. Some pieces were clearly the sporangiophores of mucoraceous fungi, bearing columellae, others were dematiaceous conidiophores, and the sporing heads of aspergilli were also frequent.

Non-classified spores. This category included a number of readily identified as Alternaria, Helminthosporium, Epicoccum, Ganoderma and other coloured basidiospores and rust uredospores, together with a number of unidentified spores. None of these categories was present in sufficient numbers for separate classification.

\section{Results from culture methods}

Pectic jelly AVST slides. With the methods described above, the dilution plating was carried out on 17-19 December, with 1/50 dilutions (Table 4). Probably all that can be said is that the method appears to be promising.

Petri plate exposures. In a single estimation by exposing a Petri dish for $15 \mathrm{sec}$. 90 colonies of fungi were obtained. With longer exposures the number of colonies was too great to be counted.

The species of fungi recovered in culture by these two methods were not studied in detail but the following were recorded: *Absidia corymbifera (Cohn) Sacc. \& Trot., * A. ramosa (Lindt) Lendner, Mucor racemosus Fresen., *M. pusillus Lindt, * Rhizopus arrhizus Fischer, *Aspergillus flavus Link, *A. fumigatus Fresen., *A. nidulans (Eidam) Wint., *A. niger van Tieghem, $A$. ochraceus Wilhelm, A. glaucus series, *A. terreus Thom, Trichoderma viride Fr., Cladosporium herbarum Fr., Penicillium piceum Raper \& Fennell, Chaetomium globosum Fr. 
Most of these species are fast growing, and on plates they completely obscured any slow growing fungi. Those organisms marked * are potentially pathogenic to animals.

Table 4. Numbers of colonies on dilution plates from pectic jelly slides

\begin{tabular}{|c|c|c|c|c|c|}
\hline \multirow{2}{*}{$\begin{array}{l}\text { Portion of trace, } \\
17-18 \text { Dec. } 1956\end{array}$} & \multicolumn{4}{|c|}{ Numbers of colonies/plate. Dilutions } & \multirow{2}{*}{$\begin{array}{l}\text { Estimated } \\
\text { equivalent, } \\
\text { spores/m. }\end{array}$} \\
\hline & $1 / 50$ & $1 / 2,500$ & $1 / 125,000$ & $1 / 6,250,000$ & \\
\hline $17.00-23.00 \mathrm{hr}$. & 260 & 7 & 一 & 2 & 4,194 \\
\hline $23.00-05.00 \mathrm{hr}$. & 480 & 74 & 4 & 3 & 6,944 \\
\hline 05.00-11.00 hr. & * & 440 & 42 & $\mathbf{1}$ & $\mathbf{3 5 0 , 0 0 0}$ \\
\hline $11.00-17.00 \mathrm{hr}$. & $*$ & $*$ & 104 & 30 & $3,610,000$ \\
\hline
\end{tabular}

\section{DISCUSSION}

The most interesting result of this aerobiological study seems to be the very high density of airborne spores encountered in an ordinary cowshed. The spore content of the air was high throughout the $24 \mathrm{hr}$., and an exceptionally heavy spore load followed the disturbance of the hay, indicating that the 'dust' raised in cowsheds may be composed chiefly of fungus spores and hyphae. Very few plant, animal or mineral fragments were seen on the slides from the AVST.

Of the different spore types observed the Aspergillus-Penicillium type and the Mucor type are usually of minor importance in outdoor air spora sampled with the AVST and have never before been reported in such large numbers, although they may appear in some numbers on gravity plate cultures. These groups have been shown to increase in numbers in air in winter (Richards, 1954; Vallery-Radot, Halpern, Secretain \& Domart, 1950), possibly associated with the feeding of farm livestock with hay. It seems certain that small local concentrations of spores must be set up every time a hay or straw stack is disturbed. The high number of hyphal fragments is also a feature not previously reported and may show that the spores are released into the air with sufficient friction to break off the complete sporophore from its substrate when the hay is pulled apart and placed in the mangers.

The virtual absence of several of the more prominent spore types found in the outdoor air, such as ascospores, basidiospores, and Erysiphe conidia is perhaps satisfactorily explained by the general diminution of the outdoor air spora in winter, the density of the deposit on the slides and the dryness characteristic of the cowshed. The two newly reported and easily recognized categories of airborne spores are the Streptomyces- and the Monotospora-types. The former may be the source of many of the streptomycete colonies frequently occurring as laboratory contaminants, while the latter seems to be an 'indicator species' for over-heated hay, as it is rare in good quality samples.

When the pathogenic significance of the fungi found in the cowshed air is considered it is necessary to deal with individual species of fungi. In the list given above those species marked with an asterisk $\left(^{*}\right)$ are potentially pathogenic to men or animals and as these represent the majority of the Aspergillus and mucoraceous colonies obtained, most of the spores classified visually in these two categories belonged to these species. The inhalation of $A$. fumigatus spores by animals can produce pulmonary infection and the ingestion of mucoraceous spores is thought to 
be one infection route for mucormycosis of the alimentary tract in animals, e.g. guinea-pigs (Ainsworth \& Austwick, 1955 a). The possibility of an initial respiratory infection leading to mycotic abortion in cattle was discussed by Bendixen \& Plum (1929) and the normal spore concentrations in the atmosphere of a cowshed obtained during the present study may provide a useful basis for investigating the little known epidemiology of these mycoses.

The possible value of these findings in the medical field is probably not so much concerned with the direct pathogenicity of the fungi as with their ability to act as allergens. Hyde, Richards \& Williams (1956) showed how the spores of certain species of fungi produce allergic respiratory symptoms, e.g. asthma, in subjects not normally exposed to concentrations of spores greater than are found in the outdoor air. Ill-defined respiratory trouble associated with the handling of mouldy hay and straw often referred to as 'farmer's lung' (Fuller, 1953; Frank, 1958) has yet to be related to a specific cause, but with spore concentrations in air as high as those recorded in this work it should be possible to locate one or more sensitizing agents among the many different components present in cowshed air.

Estimated spore intake of cattle and man. According to Hall \& Brody (1933) a standing cow has the following air intake (subject to a $20 \%$ coefficient of variation): Tidal air (volume inhaled at one inspiration), $3800 \mathrm{ml}$; respiration rate, 27/min.; minute volume (volume of air inspired/min.), $100 \mathrm{l}$. From these data it may be calculated that in $10 \mathrm{~min}$. a standing cow respires from about $1 \mathrm{~m} .^{3}$ air, or from $6 \mathrm{~m} \cdot{ }^{3} / \mathrm{hr}$.

If a continuous spore load of 100,000 spores $/ \mathrm{m} .{ }^{3}$ be assumed, then the spore intake of each cow over the $19 \mathrm{hr}$. she is in the cowshed (not of course standing for the whole time) is of the order of 600,000 spores/hr. or $11,400,000$ spores daily. As there are two peak periods involved each with a possible duration of 1-2 hr., one $16 \mathrm{hr}$. exposure at 100,000 spores $/ \mathrm{m}^{3}$ and one of $3 \mathrm{hr}$. at $16,000,000$ spores $/ \mathrm{m} .{ }^{3}$ would give a total intake during the housed hours of the order of $297,600,000$ spores.

In man the tidal air is about $500 \mathrm{ml}$., the respiration rate $15-20$ and the minute volume $10 \mathrm{l}$., so that the intake of spores may be taken direct from the figures obtained from the AVST (Tables 2 and 3). Total exposure, however, would differ considerably, but in this case would include breathing for some time in each of the three peak periods during the day.

Thanks are offered to Dr A. W. Stableforth and Dr G. Slavin for allowing me to undertake the sampling in a cowshed housing an experimental herd at Weybridge and to Mrs J. D. Cartner for her technical assistance. Acknowledgement is also made to the Administrators of the Colombo Plan for the award of a fellowship which enabled the work to be undertaken. Thanks are also offered to Mr P.K.C.Austwick of Weybridge for guidance, and to Professor P. H. Gregory for facilities for this work in the Department of Botany, Imperial College of Science and Technology, London, S.W. 7. 


\section{REFERENCES}

Ainsworth, G. C. \& Austwick, P. K. C. (1955a). A survey of animal mycoses in Britain: general aspects. Vet. Rec. 67, 88.

Arnsworth, G. C. \& Austwick, P. K. C. (1955b). A survey of animal mycoses in Britain: mycological aspects. Trans. Brit. mycol. Soc. 38, 369.

Bendixen, H. C. \& Plum, N. (1929). Schimmelpilze (Aspergillus fumigatus und Absidia ramosa) als Abortusursache beim Rinde. Acta path. microbiol. Scand. 6, 252.

Frank, R. C. (1958). Farmer's lung - a form of pneumoconiosis due to organic dusts. Amer. J. Roentgenol. 79, 189.

Fuller, C. J. (1953). Farmer's lung: a review of present knowledge. Thorax, 8, 59.

Gregory, P. H., Hirst, J. M. \& LAST, F. T. (1953). Concentrations of basidiospores of the Dry Rot fungus (Merulius lacrymans) in the air of buildings. Acta allerg., Kbh. 6, 168.

Hall, W. C. \& Brody, S. (1933). Growth and development. With special reference to domestic animals. Mo. agric. Exp. Sta. Res. Bull. no. 180, 1.

Hirst, J. M. (1953). Changes in atmospheric spore content: Diurnal periodicity and the effects of weather. Trans. Brit. mycol. Soc. 36, 375.

Hyde, H. A., Richards, M. \& Williams, D. A. (1956). Allergy to mould spores in Britain. Brit. med. J. 2, 886.

Maunsell, K. (1954). Concentration of airborne spores in dwellings under normal conditions and under repair. Int. Arch. Allergy, 5, 373.

REHE, R. D. (1927). Biochemical decomposition of cellulosic materials with special reference to the action of fungi. Ann. appl. Biol. 14, 1.

Richards, M. (1954). Atmospheric mould spores in and out of doors. J. Allergy, 25, 429.

Rolle, M. \& Kolb, E. (1954). Zur Frage des Vorkommens von Schimmelpilzen (Mucoraceae, Aspergillaceae) im Magen-Darmkanal der Haustiere. Z. Hyg. InfektKr. $139,415$.

SREeramulu, T. (1958). Studies on the dispersal of spores in the air, with special reference to some pathogenic fungi. Ph.D. thesis, London University.

Vallery-Radot, P., Halpern, B. N., Secretain, A. \& Domart, A. (1950). Étude de la nature et de la densité de la flore mycologique dans l'atmosphère de Paris durant l'année 1948. Acta allerg. Kbh. 3, 179. 